\title{
Understanding Disaster Risk Reduction Strategies in Schools of Developing Urban Settlement: Study on Dhaka City, Bangladesh
}

\author{
Md Mostafizur Rahman \\ Assistant Professor, Dept. of Disaster and Human Security Management \\ Bangladesh University of professionals, Dhaka, Bangladesh \\ Tel: 88-017-6902-8446 E-mail: amimostafiz@gmail.com \\ Irtifa Alam Nabila \\ Assistant Professor, Dept. of Disaster and Human Security Management \\ Bangladesh University of professionals, Dhaka, Bangladesh \\ Tel: 88-017-6902-1925Ｅ-mail: Irtifa.alam@bup.edu.bd
}

Farhana Islam

Graduate Student, Dept. of Geography and Environment University of Dhaka, Dhaka, Bangladesh

Tel: 88-016-2061-0705 E-mail: farhanaislam1280@gmail.com

Farah Tasnim

Graduate Student, Dept. of Disaster and Human Security Management Bangladesh University of professionals, Dhaka, Bangladesh Tel: 88-015-2149-8000Ｅ-mail: farahprova25@gmail.com

Received: February 3, 2020 Accepted: February 23, 2020 Published: March 3, 2020

doi:10.5296/jad.v6i1.16593 URL: https://doi.org/10.5296/jad.v6i1.16593 


\section{Abstract}

The study investigates the existing scenario of disaster risk reduction (DRR) principles and practices in the schools of developing urban settlement. Bangladesh, being vulnerable due to disaster, has severe condition in some coastal areas due to climate change. People migrate to the capital city, Dhaka for better opportunity. In the last few years, DRR agenda is included in education programs to decrease the number of casualties and distressed people and reduce disaster losses. Increasing susceptibility begets higher risk; hence the study has been conducted focusing on urban disasters, especially Earthquake and Fire hazard. This study follows comprehensive global school safety framework (GADRRRES, 2017) to find out the school safety plan of schools in Dhaka city. It apprehended the viewpoints of children, teachers and local people about the situation of DRR education, plan and practices in schools by conducting FGD, Questionnaire survey. It has been observed although all respondents understand the importance of DRR, they lack interest of implementing it. Some schools run by the Government are following Drill, their condition are better than private schools considering DRR practices. Several strategic recommendations have been made at the end of the study to improve DRR preparedness in schools of Dhaka.

Keywords: Disaster Risk Reduction, School, Preparedness, Urban disaster, Implementation challenges

\section{Introduction}

Disaster interrupts and disrupts the normalcy of community by destroying lives and properties. It is the consequence of the interaction of hazardous events with the community's exposure and vulnerability. The amalgamation of education, awareness and knowledge are crucial to build resilience against the inevitable occurrence of extreme natural events (Wisner, 2006). Natural hazards are unavoidable; there is no way to impede these. Nevertheless, it is assertive that the chances of hazard to turn into disaster can be reduced by lessening community's vulnerability. Community's vulnerability can be raised from physical, social, economic and environmental sector. Proper information about these sectors can help understand and eliminate the challenges to reduce certain disaster risk. Disaster risk reduction (DRR) contains the principles and strategies to reduce the probability of hazard to turn into disaster. Therefore, proper education, knowledge and awareness (Wisner, 2006) should be served among communities and most certainly among schools. School can act as multipurpose system considering disaster risk, where community can get benefits from school in several ways. The culture of DRR practice among school children will be effective to confront any sort of natural and anthropogenic calamities.

Whole community and the nation can be well prepared for disasters if school children are prepared properly. Extensive endeavors have also been specified to assimilate DRR in the segment of education (Ronan, 2014). School can be hub to transfer disaster related knowledge from the facilitators to the community, and vice versa. After family, the school is the second most important primary social system responsible for the development of values for human behavior, knowledge, behavior, and social co-ordination. It has been established when children are encouraged and assisted by adults and are guided with enough knowledge 
and skills; it can bring about significant changes in protecting themselves as well as in communities to acclimatize to climate change and lessen the risk of disasters (Haynes and Tanner, 2015; Webb and Ronan, 2014; Tanner, 2010). Schools can be used for multipurpose activities as well. It can not only be the safe learning place for children, but also for the community. It can be shelter for the community people during disaster. Unfortunately, there are few studies that investigate the DRR practices in schools and the challenges in implementation.

Children are the future leader for any nation. They are contemplated as one of the utmost vulnerable groups in a calamity. WHO (2011) gave approximations that fatalities consist of $30-50 \%$ children due to natural hazard events. It is urgent needs to provide disaster risk-free environment for the children. Education is a significant medium through which children can take part in disaster risk reduction (Amri, 2015). In the universal commitment for DRR, Schooling has always been one of the priorities, as expressed in the Yokohama Strategy (United Nations, 1994), the Hyogo Framework for Action (HFA) 2005-2015 (UNISDR, 2005), and the Sendai Framework for Disaster Risk Reduction 2015-2030 (UNISDR, 2015).

In Bangladesh, the feasibility has been verified to use school systems as a position to reduce the risk of disaster. Studies have found that there are many positive outcomes that can be assumed to be mainstreaming of DRR through Bangladesh's school education system. School-parent interaction and focal points for primary development in the Bangladesh community are the opportunities for improving the current disaster risk reduction situation.

Dhaka city is the capital of Bangladesh and one of the most populous and disaster-prone cities in the world. It is a rapid growing city without proper planning. With the increasing population, the demand of the infrastructures and the schools are also increasing without proper plan. Under these circumstances' children are more vulnerable, while they are in schools. Without giving school children a disaster risk-free environment, the development process can collapse at any time. Which is evident from Kashmir Earthquake in 2005, Philippines Landslide in 2006 (Tuladhar et al., 2014); Haiti Earthquake in 2010, Nepal Earthquake in 2015 (Paci-Green et al., 2015).

With all these circumstances, this study made an attempt to understand the current status of DRR practices and existing challenges to implement DRR in the schools of Dhaka city.

\section{Study Area}

Schools from four notable places of Dhaka city (Figure 01): Mirpur, Banasree, Dhanmondi and Old Dhaka (around Lalbagh area) were selected to collect data. Mirpur area is in the most destructive liquefaction zone. An event of earthquake of medium to high magnitudes can trigger destructive liquefaction damage in the city (Stott, 2014). Also, narrow road and fragile infrastructure make Mirpur more vulnerable for fire and earthquake. Banasree and Dhanmondi are also vulnerable areas of Dhaka city. Old Dhaka is intended as one of the most vulnerable areas in the world especially for earthquake and fire incidents due to high density of population, unplanned structural development. 


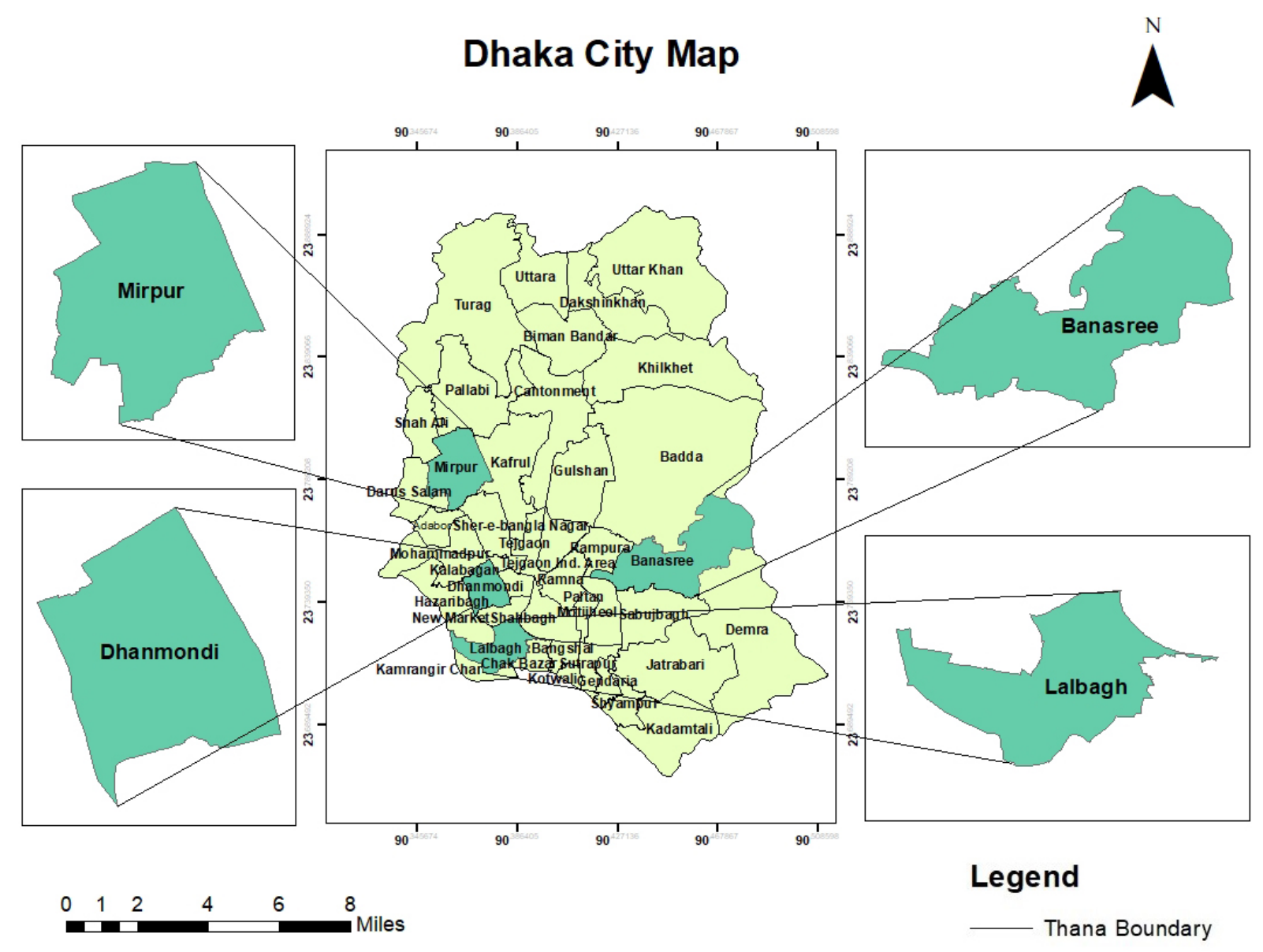

Figure 1. Study Area

Hence, proper awareness needs to be disseminated among community people and a culture of DRR needs to be established. And to disseminate DRR knowledge, school is the greatest option and educating children about DRR is the best investment.

\section{Methodology}

Mixed methods were employed by focusing on three different responders and beneficiaries. The targeted respondents are school's students, school administrative bodies and the parents. Mixed data were collected from both primary and secondary sources.

Questionnaire survey with interview was carried out based on group categories: School children, parents, teachers, adjacent community, administrative bodies etc. Focus Group Discussion (FGD) was conducted with both parents and teachers as well. Practical observation was made to get information around the schools and to check the availability of structural DRR measures in schools. Interactive presentation session was conducted, where Question-Answer session had separate session with a purpose of getting to know the DRR knowledge in schools. Comprehensive school safety (CSS) framework (GADRRRES, 2017) 


\section{Macrothink}

was followed to understand the DRR practices in schools of Dhaka city.

\section{Results and Discussion}

\subsection{School Category}

The intended focus was to cover all types of school (government, private; kindergarten, primary, secondary) to get actual picture of DRR practice in schools of Dhaka city. Thus, a total of 52 schools were selected randomly to distinguish DRR practices and difficulties to execute DRR in schools (Table 1).

Table 1. Number of schools selected for survey in Dhaka city

\begin{tabular}{|l|l|l|}
\hline Area & Number of Schools & Government Schools \\
\hline Mirpur & 20 & 3 \\
\hline Banasree & 10 & 0 \\
\hline Dhanmondi & 12 & 4 \\
\hline Old Dhaka & 10 & 2 \\
\hline
\end{tabular}

\subsection{Disaster Knowledge}

Students, parents and teachers were interviewed about urban disaster knowledge as multi-hazards are present in those selected areas. For instance, Mirpur and Banasree area have a prevalence of water logging and earthquake problem whereas Dhanmondi and Old Dhaka are more concerned about earthquake and fire incidents. It was observed the students and teachers in Old Dhaka and Banasree area have more acquaintance about disaster (earthquake and fire incidents) due to some past tragedies; but lack in risk reduction knowledge. Ironically these schools lack the concept of having Disaster Management body at schools as well.

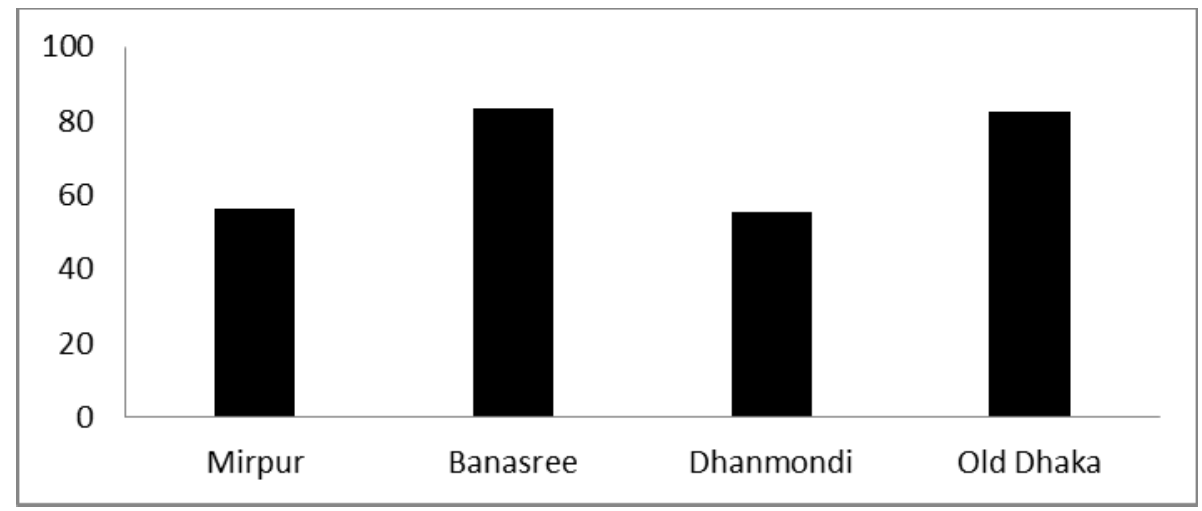

Figure 2. Students Perceiving Knowledge regarding Disaster 


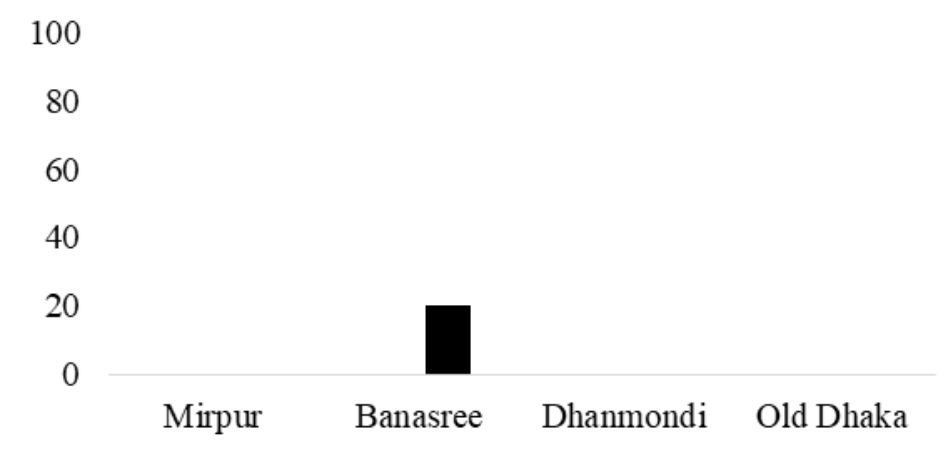

Figure 3. Disaster Management body (\%)

\subsection{Multipurpose Schools}

Utilizing schools for multipurpose can be beneficial for community if used as shelter in disaster response and recovery phase and also as community gathering during normalcy. Conversely multipurpose use of the schools (e.g. for business purpose) can increase vulnerability. More than 50\% schools of Dhaka city utilizing schools for multipurpose (e.g. business, shopping mall) without following proper DRR policy. Most of them are unaware and ignorant of using school buildings in different disaster phases. Altogether these factors engender critical vulnerabilities for schools especially in Old Dhaka. Banasree and Mirpur area can be considered new Dhaka, where different business activities have been observed. Several schools are here just in one floor, where other floors are available for office and shopping mall which can lead more vulnerable situations for schools.

\subsection{Understanding School Children's Contribution in DRR}

Children are not exposed to disasters only; they can take part in playing crucial role in DRR. They can put great contribution to disseminate DRR information to their parents who are the part of surrounding community, and thereby the whole community can reduce disaster risk. Field Study shows that the people of schools in Mirpur and Banasree area have high percentage in this category where Dhanmondi and Old Dhaka show poor percentage. It shows mixed understanding of the school people in Dhaka city. It is beyond the study that why parents and teachers have poor understanding to identify the school children's contribution in DRR. New Dhaka shows better understanding on this issue. One probable explanation could be that the schools in new Dhaka are new schools with children from different background. Their parents are mostly migrated from outside Dhaka, and they have some knowledge that their children can contribute in DRR. It is a good sign that new people in Dhaka city are showing the importance about DRR in schools. 


\section{Macrothink}

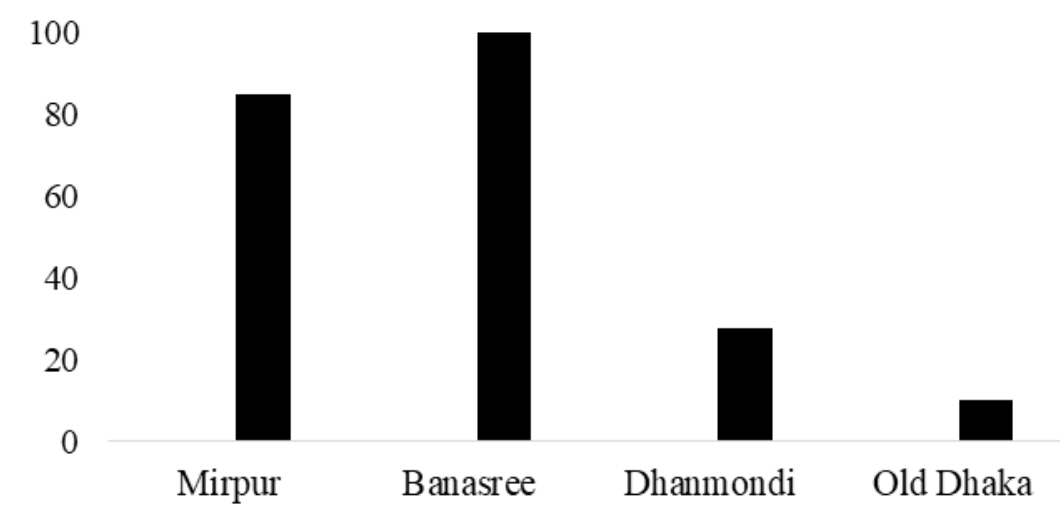

Figure 4. Children's contribution in DRR (\%)

\subsection{Fire and Earthquake Safety Measures}

Even though, all school communities and other respondents of Dhaka city recognize the urgency of having DRR strategy, plan and its implementation; their current practices bespeak poor performance. Most of the schools have less than 50\% fire and earthquake safety measures (depicting both from interview and observation).

Fig. 4 and 5 show the result of fire and earthquake safety measures collected form interview. School authorities (both teachers and administrative bodies) were interviewed about their measures (mainly nonstructural DRR measures). Schools of Old Dhaka evince high percentage in case of earthquake measures compared to other area's schools as it is the most vulnerable area for earthquake and fire incidents. After facing a handful of tragedies (such as Nimtoli fire tragedy, Chawkbazar fire tragedy); there have been some activities running on by Government and NGO.

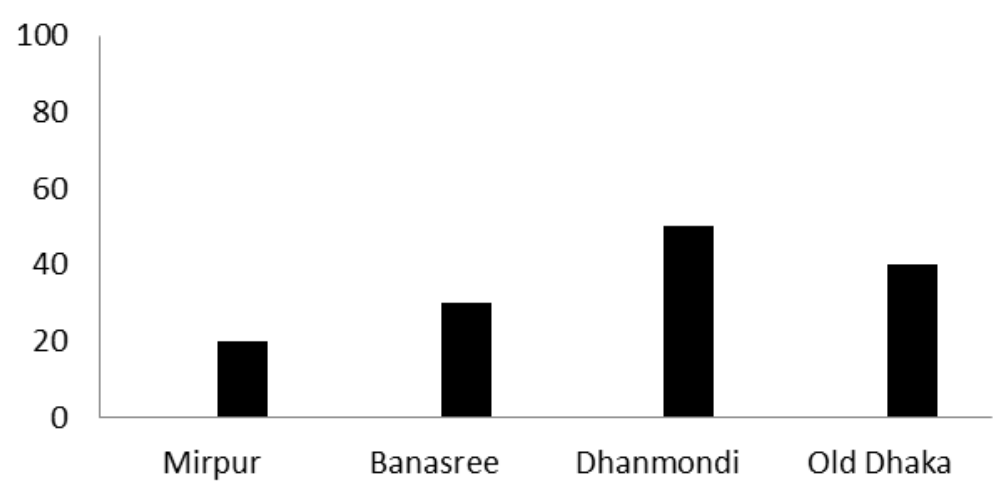

Figure 5. Fire Safety Measures (\%, Interview) 


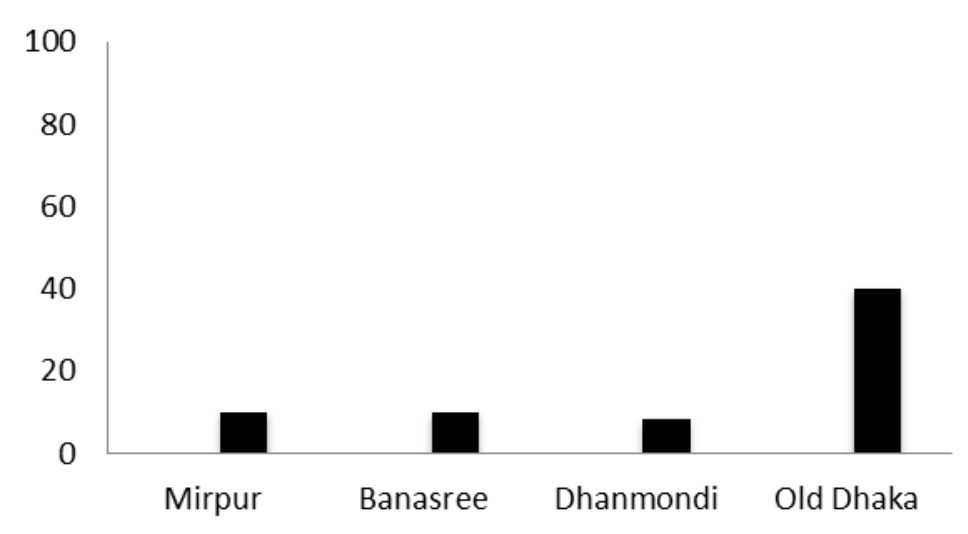

Figure 6. Earthquake Safety Measure (\%, Interview)

But the activities are merely adequate for eradicating the risk due to the infrastructural alignment in this area. Figure 06 unveils the poor structural DRR condition in schools of Dhaka city. It manifests high fire and earthquake risk of the schools of Dhaka city. Lack of water source, fire detecting system, open space, faulty evacuation route can lead to greater jeopardy.

\subsection{Community-School Interaction}

Community and school interaction are important to make the community resilient. It aspires each group to form a strong bonding that helps to reduce the risk of any disasters. The possible way to achieve it through drill exercise that arranged by schools where community can participate. Community participation in drill exercise is very poor in schools of Dhaka city even though they are aware of the importance of this participation. Old Dhaka shows a growing and promising concern in this arena comparing to all; $20 \%$ respondents feel the necessity of it. 


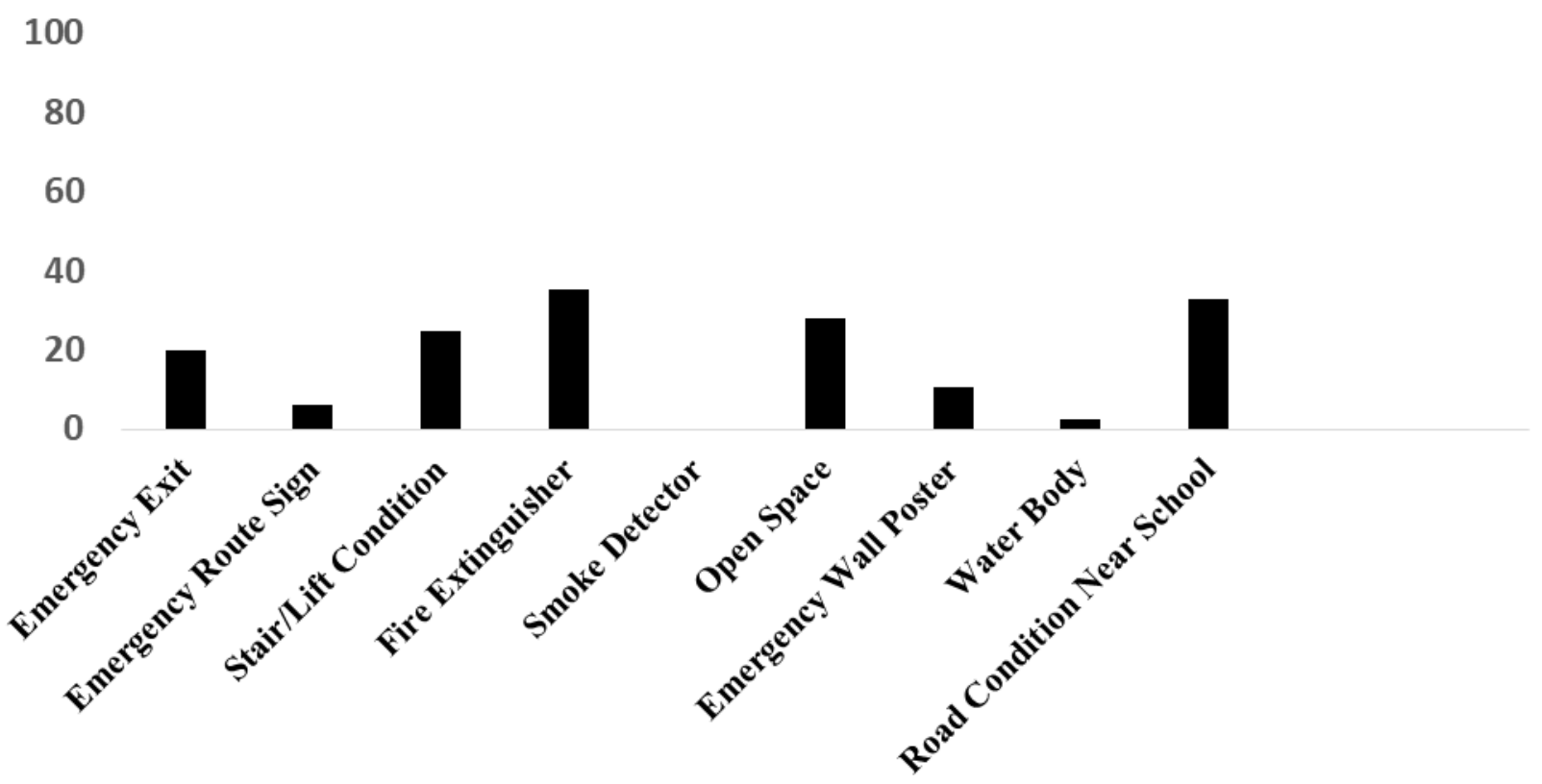

Figure 7. Fire and Earthquake safety structural measures from observation (\%)

\subsection{Green School Practice}

Schools should have green areas around its place, to help in climate change adaptation and also to protect and reduce risk from disaster. Dhanmondi, being an economically sound area, have some green places around the schools; however other areas show few percentages in this category. One possible explanation of having more greenery areas in schools of Dhanmondi is that this can attract the people living around here who have considered the beautification of schools.

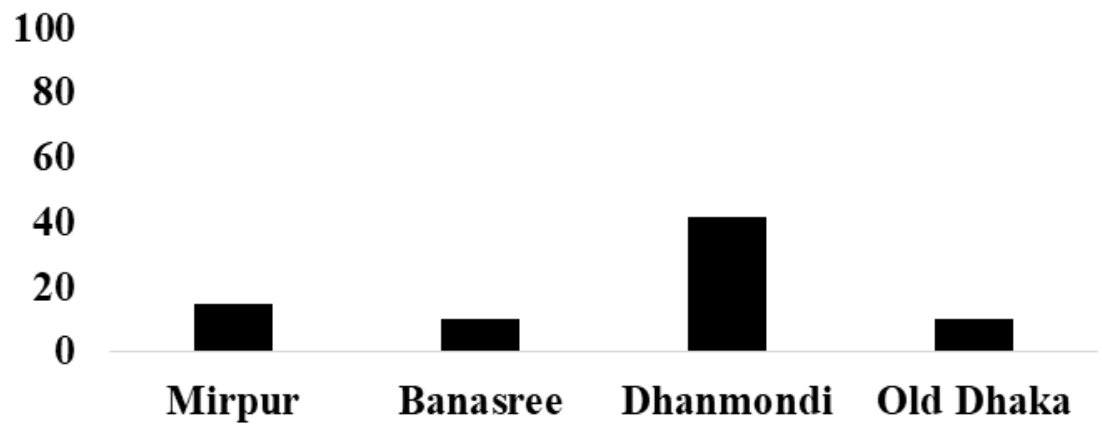

Figure 8. Green practice around school (\%) 


\section{Macrothink}

\subsection{Water, Sanitation and Hygiene}

Most schools show poor healthy life practice to reduce different disease related risk (Fig. 11). Most schools do not meet the need of proper hygiene facilities both for students and teachers. The schools must set examples to the students regarding healthy life practice to combat any sort of health-related disease.

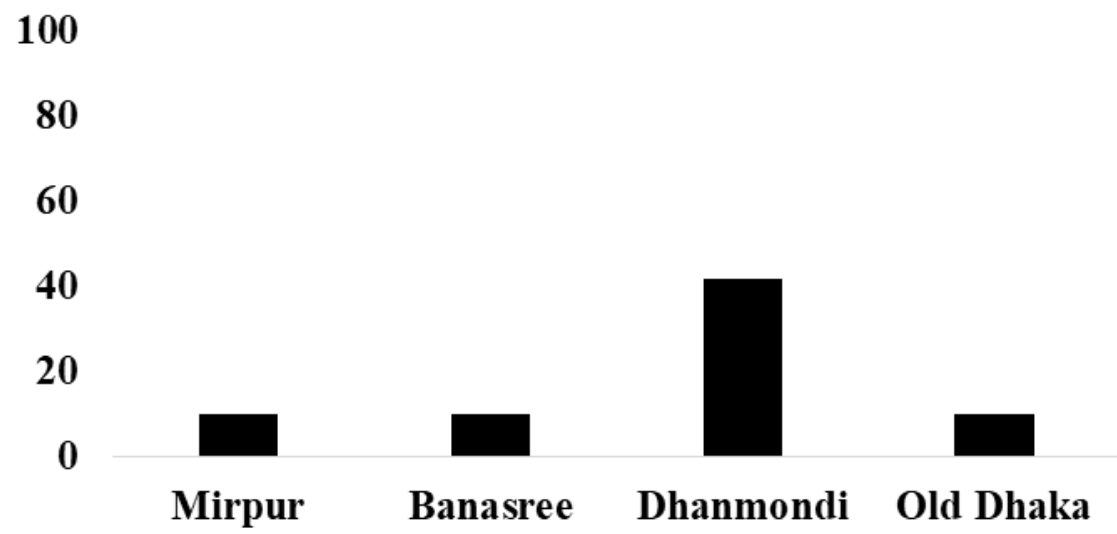

Figure 9. Water, Sanitation and Hygiene practice (\%)

\subsection{Awareness About Emergency Calling}

The propensity and perception of calling in the emergency number "999" is not mature enough among the students. Surprisingly the trend is found downward even among the teachers as well. Most of them have grasp on the knowledge about disaster but lack the consciousness of what to do in emergency situation. As it was stated earlier, it falls under public apathy. Among four areas, Dhanmondi and Banasree show poor indication. The reason Old Dhaka and Mirpur present positive trend is due to the drill and awareness program.

\section{Recommendations}

These recommendations are made upon the gaps and challenges identified in the upper section. The main purpose of raising awareness among students, teachers and other relevant authorities is to reduce the risk of disaster. To reduce this risk, school safety programs should be complementary to school preparation and community deployment as well as organization deployment for civil society participation. The following recommendations for each stakeholder (schools, local and central authority) may set up as a good preparation measurement.

\subsection{Recommendation for School}

1. All schools (including schools from both urban and rural areas) should follow Comprehensive School Safety Framework (GADRRRES, 2017).

2. The basic concept of disaster, risk and disaster risk reduction should be provided and practiced in all schools. 


\section{Macrothink

3. Teachers, school authorities should have especial training program where they will learn how to perform during disaster, and how to teach their school children about disaster risk.

4. Schools ought to have a disaster management governing body to monitor the indicators of school safety.

5. School should observe DRR exercise where parents, surrounding community can participate with the school bodies.

6. School should have disaster preparedness plan and they should also prepare budget plan to submit to the Government. School budgets should be kept aside to acquire and stock the necessary relief and preparation items. Different safety measures such as earthquake toys, fire safety toys, smoke detectors, sprinklers, emergency lighting, water, food and medicines must be available in all schools.

7. School should be built in such way that it can be properly used for multi-purpose. Community people can gather, make meeting here, and it can also be used as shelter during any disaster.

8. Students should have practice of gardening around school, to combat with the current climate change condition and to reduce disaster risk as well.

9. Proper water, sanitation and hygiene practice should be conducted in schools. Students should have special class and training on it.

10. School's location should in such place where other facilities (fire station, water bodies, open space, good road condition) are available.

11. All schools should have evacuation route, and they should practice how they can evacuate in emergency situation.

12. In the days of earthquake or fire, schools should have sufficient stock of emergency supplies.

13. Schools should have proper linkage and communication practices with central, local Government and with the surrounding community.

\subsection{Recommendation for Guardians}

1. Considering the severity of disaster and children as one of the most vulnerable groups; parents should inquire about school's safety.

2. Contact the school authorities as part of them or as part of a larger group and try to understand how the school is prepared for such incidents. If the school does not have an emergency plan, then these measures must be taken so that it can be set up quickly.

3. Parents can work for disaster preparation and can provide education to their children, who can use it when an event is raised in school.

4. Parents can take care of the importance of school protection for their elected 
representatives and the importance of implementing this crucial agenda and implementation of surveillance policy.

\section{Conclusion}

The role of schools in society is very important. The dynamic, energetic and influential power of children can alter and support in generating awareness among the community. Their contribution can be visualized in a unique way for solving local solutions.

The focus of preparation is spreading awareness and training of most of the teachers and urban volunteers. Although the study found there is no suitable emergency management system in practice. The communication channel between parents and school is narrow. There is no legal policy under which the schools are required to operate these steps in pre-defined quality and standards. These incidents lead to misunderstandings and misrepresentation because schools follow their own understanding of their activities and it can give wrong impression to children. There is no structured evacuation and retrofitting system designed for government schools or for private schools. The building is standing on a risky land, in which there is a soft soil, which is filled up and can affect the fluid after the earthquake and cruel fire.

Although there are often significant areas of education in the areas of flood trends and cyclone prone areas, important education is provided immediately. On the contrary, there is no preparation and risk assessment for preparing and preparing risk for schools in urban areas where it has been predicted that the Dhaka city can strike huge earthquake any time. There have been frequent fire incidents in Dhaka city. The water logging, poor waste management etc. are frequent here. However, few schools have been observed some DRR measures which are not still enough.

Children are one of the most vulnerable groups in any society. And they can also contribute to reduce disaster risk. Schools can play crucial role to prepare a community against disaster. Community-school interaction is integral part to face disaster. If schools are not safe for children and they don't have interaction with the surrounding community, then there will be worst situation during disaster. Dhaka city has been considered one of the most risk-prone areas for earthquake and fire incidents. Disaster can strike anytime, and if it happens in this current poor DRR condition, the consequence will be catastrophic.

\section{Acknowledgements}

Authors would like to sincerely acknowledge the cooperation of Center for Higher Studies and Research of Bangladesh University of Professionals for funding this work. Authors would also like to acknowledge the students of the Department of Disaster and Human Security Management for their continuous support during the tedious survey to collect data.

\section{References}

Amri, A. (2015). Challenges in implementing disaster risk reduction education: Views from the frontline in Indonesia. 
Global Alliance for Disaster Risk Reduction and Resilience in the Education Sector. (2017). Comprehensive School Safety Framework.

Haynes, K., \& Tanner, T. M. (2015). Empowering young people and strengthening resilience: Youth-centred participatory video as a tool for climate change adaptation and disaster risk reduction. Children's Geographies, 357-371. https://doi.org/10.1080/14733285.2013.848599

Paci-Green, R., Pandey, B., \& Friedman, R. (2015). Safer schools, resilient communities: a comparative assessment of school safety after the 2015 Nepal earthquakes.

Ronan, K. (2014). Advances and continuing challenges towards HFA2 and post-2015 background chapter.

Stott, C., \& Nadiruzzaman, M. (2014). Disaster Risk Reduction in Dhaka City: From Urban Landscape Analysis to Opportunities for DRR Integration. World Vision International.

Strategy, Y. (1994). Plan of Action for a Safer World-Guidelines for Natural Disaster Prevention, Preparedness and Mitigation. In World Conference on Natural Disaster Reduction, Yokohama, Japan (pp. 23-27).

Tanner, T. (2010). Shifting the narrative: child - led responses to climate change and disasters in El Salvador and the Philippines. Children \& Society, 24(4), 339-351. https://doi.org/10.1111/j.1099-0860.2010.00316.x

Tuladhar, G., Yatabe, R., Dahal, R. K., \& Bhandary, N. P. (2014). Knowledge of disaster risk reduction among school students in Nepal. Geomatics, Natural Hazards and Risk, 5(3), 190-207. http://dx.doi.org/10.1080/19475705.2013.809556

UNISDR. (2005). Hyogo framework for action 2005-2015: building the resilience of nations and communities to disasters. Geneva, Switzerland.

UNISDR. (2015). Sendai Framework for Disaster Risk Reduction 2015- 2030, UNISDR.

Webb, M., \& Ronan, K. R. (2014). Interactive Hazards Education Program for Youth in a Low SES Community: A Quasi - Experimental Pilot Study. Risk analysis, 34(10), 1882-1893. https://doi.org/10.1111/risa.12217

WHO. (2011). Disaster Risk Management for Health Fact Sheets: Child Health. Retrieved from https://www.who.int/hac/events/drm_fact_sheet_child_health.pdf

Wisner, B. (2006). A review of the role of education and knowledge in disaster risk reduction.

\section{Copyright Disclaimer}

Copyright for this article is retained by the author(s), with first publication rights granted to the journal.

This is an open-access article distributed under the terms and conditions of the Creative Commons Attribution license (http://creativecommons.org/licenses/by/4.0/). 